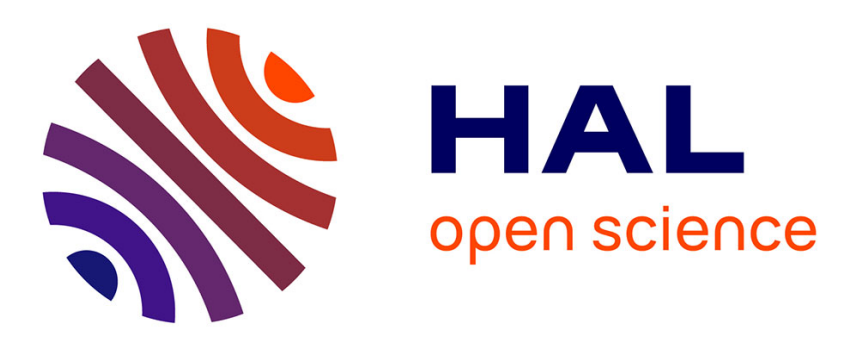

\title{
Investigation of the thermal stability and fire behavior of high performance polymer: A case study of polyimide
}

\author{
Aditya Ramgobin, Gaelle Fontaine, Serge Bourbigot
}

\section{To cite this version:}

Aditya Ramgobin, Gaelle Fontaine, Serge Bourbigot. Investigation of the thermal stability and fire behavior of high performance polymer: A case study of polyimide. Fire Safety Journal, 2020, pp.103060. 10.1016/j.firesaf.2020.103060 . hal-02926414

\section{HAL Id: hal-02926414 \\ https://hal.univ-lille.fr/hal-02926414}

Submitted on 31 Aug 2020

HAL is a multi-disciplinary open access archive for the deposit and dissemination of scientific research documents, whether they are published or not. The documents may come from teaching and research institutions in France or abroad, or from public or private research centers.
L'archive ouverte pluridisciplinaire HAL, est destinée au dépôt et à la diffusion de documents scientifiques de niveau recherche, publiés ou non, émanant des établissements d'enseignement et de recherche français ou étrangers, des laboratoires publics ou privés. 


\title{
Investigation of the thermal stability and fire behavior of high performance polymer: A case study of polyimide
}

\author{
Aditya Ramgobin, Gaëlle Fontaine, Serge Bourbigot* \\ Univ. Lille, ENSCL, UMR 8207, UMET, Unit Mariaux et Transformations, F 59 000, Lille, France
}

\section{A R T I C LEIN F O}

\section{Keywords:}

High-performance polymer

Polyimide

Fire reaction

Thermal stability

Decomposition pathway

\begin{abstract}
A B S T R A C T
This article reports the thermal and fire behaviors of a high performance polymer, namely polyimide (PI). These behaviors were investigated using different techniques and tests, i.e., pyrolysis-Gas-Chromatography/MassSpectrometry (py-GC/MS) and TGA coupled with a Fourier Transform InfraRed spectrometer (TGA-FTIR), and mass loss cone (MLC) at different heat fluxes. It was observed that the thermal stability of PI strongly depends on the oxygen concentration. The main identified gases released during thermal degradation are: carbon dioxide, carbon monoxide, water and organic compounds (phenol, aniline, cyanobenzene, dicyanobenzene, 4-aminophenol, benzene, 2-(4-hydroxyphenyl)isoindoline-1,3-dione, phthalimide, dibenzofuran, and diphenylether). The ignition of PI in MLC experiment is observed under an external heat flux of $60 \mathrm{~kW} / \mathrm{m}^{2}$. In that case, the peak of heat released by polyimide is only $30 \mathrm{~kW} / \mathrm{m}^{2}$. Based on these investigations, a possible decomposition pathway of PI is proposed.
\end{abstract}

\section{Introduction}

Despite their outstanding properties and their numerous applications, most of the polymeric materials (plastics) have one undeniable downside: they are highly flammable. In order to overcome this drawback, research was done to develop inherently flame-retardant polymeric materials, and thus result to high-performance polymers. Such polymers exhibit enhanced service-temperatures and outstanding resistance to environmental stress [1]. High performance polymers resist high temperatures, release trivial combustible volatiles, and are therefore virtually non-flammable [2]. Some of these materials are used in industries whereby extreme conditions are met. Such industries include the aeronautics industry, microelectronics, or fireproof overalls. Examples of such materials are polyimide (Kapton $®$ ) [3-5], polyetheretherketone (PEEK) [6], or aromatic polyamides such as Nomex ${ }^{\circledR}$ (or Conex $\AA$ ) or Kevlar $\AA$ (or Twaron $®)$ [7,8]. These materials all exhibit extreme fire resistance and thermal stability [9-13].

Polyimides are among the most popular high temperature/high performance polymers on the market. They are a generation of polymers with inherently rigid chains and possess high thermal and electrical properties. They are used in many fields such as microelectronics, high temperature matrices, as well as adhesives for gas separation membranes [14]. Polyimides are used in various forms such as high temperature structural adhesives, coatings, films, or laminating resins [15]. Their high temperature resistance makes them enviable polymeric materials for aeronautics and transport industry [16]. Their excellent thermal stability is attributed to the inert imide ring and high interchain interactions [17]. It is therefore of interest to study its thermal and fire behavior to extract invaluable information about the mode of action of its decomposition.

One of the most popular methods adopted to investigate the thermal stability of the materials is thermogravimetry analysis (TGA) in different atmosphere (atmosphere containing different oxygen levels). This provided insight to the effect that the nature of the surrounding atmosphere has on the modes of decomposition of the materials. Moreover, we attempted to elucidate the thermal decomposition pathway of the materials when they are subjected to an elevated temperature. To achieve this, the gases evolved during the thermal decomposition of the material were identified via two different methods: pyrolysis-GasChromatography/Mass-Spectrometry (py-GC/MS) and TGA coupled with a Fourier Transform InfraRed spectrometer (TGA-FTIR). However, before going into the elaboration of a thermal decomposition pathway, the fire behavior of this material was also studied. This provided further insight regarding the thermal decomposition of the PI. Finally, attempts

\footnotetext{
* Corresponding author.

E-mail addresses: aditya.ramgobin@univ-lille.fr (A. Ramgobin), gaelle.fontaine@ensc-lille.fr (G. Fontaine), serge.bourbigot@ensc-lille.fr (S. Bourbigot).
} 
at elucidating the thermal decomposition mechanism were made. This furthered the comprehension of the enhanced fire behavior and thermal stability of this material.

\section{Material and methods}

Polyimide was purchased from Goodfellow Cambridge Limited (Huntington, England). The samples size used in this study is $100 \diamond 10$ จ $1.5 \mathrm{~mm}^{3}$.

\subsection{Thermogravimetric analysis}

Thermogravimetric analysis (TGA) were conducted on a Netzsch Libra instrument. Powdered samples (or in the case of fibers, cut into small filings) of 9-10 $\mathrm{mg}$ (according to the good practice of TGA, it can be assumed the samples are thermally thin) were placed in open alumina pans and heated up to $900{ }^{\circ}$ under different percentages of oxygen and nitrogen at $10 \mathrm{C} / \mathrm{min}$. The concentration of oxygen was controlled by adjusting the ratio of oxygen to nitrogen in the entrance channel of the furnace. A total flow of $100 \mathrm{~mL} / \mathrm{min}$ was used. The oxygen levels were variable, with the lowest concentration being $2 \%$ (corresponding to a nitrogen flow of $98 \mathrm{~mL} / \mathrm{min}$ and oxygen flow of $2 \mathrm{~mL} / \mathrm{min}$ ). Before increasing the temperature, in order to ensure reliable atmosphere in the TGA oven, three cycles of vacuum/fill were performed. To ensure repeatability of the experiments, they were performed in duplicates. A confidence of $95 \%$ is achieved with the instruments used.

\subsection{TGA-Fourier Transform InfraRed spectroscopy}

Gas phase analysis were carried out in TGA Discovery (TA instruments) coupled with FTIR Nicolet spectrometer (ThermoFischer). With a length of gas cell pathway of $2 \mathrm{~m}$ long, $30.4221 .4910 .7 \mathrm{~cm}^{3}$ $1 / 48357 \mathrm{~cm}^{3}$ and an original detector from the Nicolet iS10 FTIR spectrometer using fast recovery deuterated triglycerine sulfate (DTGS) detector. Samples $(\sim 10 \mathrm{mg})$ were heated in a $250 \mu \mathrm{L}$ alumina crucible from $50 \diamond \mathrm{C}$ to $800{ }^{\circ}$ with a heating rate of $20 \diamond \mathrm{C} / \mathrm{min}$ under nitrogen atmosphere. Prior to this, samples were kept for $2 \mathrm{~h}$ under nitrogen stream to ensure the inertness of the atmosphere surrounding the sample (in the furnace). A balance purge flow of $15 \mathrm{~mL} / \mathrm{min}$ and a sample purge flow of $50 \mathrm{~mL} / \mathrm{min}$ was maintained. A transfer line with an inner diameter of 1 $\mathrm{mm}$ was used to connect TGA to the infrared cell. The temperature of the transfer line and the gas cell was kept at $225{ }^{\circ} \mathrm{C}$. Individual FTIR spectra were obtained at regular time intervals. The spectra were compared to reference spectra in order to identify the gases that were evolved. IR spectra were collected in 400-4000 $\mathrm{cm}^{-1}$ spectral range (resolution: 4, laser frequency: $15798.7 \mathrm{~cm}^{-1}$ ).

\subsection{Pyrolysis Gas Chromatrography Mass Spectrometry}

Samples (approx. $200 \mu \mathrm{g}$ ) were analyzed by pyrolysis GC/MS (Frontier Lab inc. Double Shot Pyrolyzer Py 2020iD and Shimadzu, GCMS-QP2010 SE). GC preparation was carried out with a fused silica capillary column (SLB $5 \mathrm{~ms}$ ) of $30 \mathrm{~m}$ length and $0.25 \mathrm{~mm}$ thickness. Analysis were carried out both in direct pyrolysis mode and desorption method. The temperature selection for desorption is based on TGA pattern of concerned sample with a heating rate of $10{ }^{-} \mathrm{C} / \mathrm{min}$. The initial column temperature was held at $35{ }^{\mathrm{C}}$ for a period that corresponds to desorption time followed by a temperature ramp at $10{ }^{\circ} \mathrm{C} / \mathrm{min}$ to a final temperature of $300{ }^{8} \mathrm{C}$ and isotherm for $5 \mathrm{~min}$. For direct pyrolysis the furnace is set for the degradation temperature $\left(700{ }^{\circ} \mathrm{C}\right.$ which corresponds to completion of second major degradation step, as determined by TGA) and sample is pyrolyzed for $0.5 \mathrm{~min}$. Column oven temperature is programmed in the following way: the initial column temperature was held at $35{ }^{\circ} \mathrm{C}$ for $1 \mathrm{~min}$ followed by a temperature ramp at $10{ }^{\circ} \mathrm{C} \cdot \mathrm{min}^{-1}$ to a final temperature of $300{ }^{\circ} \mathrm{C}$ and an isotherm for $20 \mathrm{~min}$. Helium was used as a carrier gas at pressure of $94.1 \mathrm{kPa}$ with a split ratio of 100 . The transfer line was maintained at $280{ }^{-} \mathrm{C}$. The MS was operated under Electron Ionization (EI) mode. An online computer using GC/MS real time analysis and PY-2020iD software-controlled GC/MS system. The eluted components were identified by library search and only significant peaks (based on signal to noise ratio) observed in the total ion chromatograms were studied and compared to a mass spectral database a mass spectral database (F-search and/or NIST MS database).

\subsection{Mass loss cone calorimetry}

The mass loss cone calorimeter (MLC) measurements were carried out on a Fire Testing Technology (FTT) mass loss calorimeter device (ISO 13927 [18], ASTM E906 [19]). The procedure involved exposing plates $\left(100001 \mathrm{~mm}^{3}, 20 \mathrm{~g}\right)$ in horizontal orientation with heating elements. Samples were wrapped in aluminum foil leaving the upper surface exposed to the heater (external heat flux of 35, 50 or 60 $\mathrm{kW} / \mathrm{m}^{2}$ and placed on a ceramic backing board at $35 \mathrm{~mm}$ from the cone base. The MLC measures the temperature of the evolved gases using a thermopile located at the top of the chimney, four thermocouples were used to calculate the heat release rate. The calibration of the heat release rate $\left(\mathrm{HRR}, \mathrm{kW} / \mathrm{m}^{2}\right)$ is performed with methane. A methane flow of $0-6.7 \mathrm{~mL} / \mathrm{min}$ is burnt above the sample holder to obtain a calibration curve of the heat release as a function of methane flow [20]. All measurements were performed at least thrice. The acceptable error of measurement is estimated at $10 \%$ for all measured values.

\section{Results}

\subsection{Thermal stability}

In order to study the thermal stability of PI, TGA was performed. This yielded TG and derivative thermogravimetric (DTG) curves that provide valuable insight on the critical temperatures concerning the thermal decomposition of PI.

As a first approach, the thermal decomposition of PI was studied under inert atmosphere (Fig. 1, Table 1). The onset of the thermal decomposition of PI ( $\mathrm{T}_{95 \%}$, temperature measured when $95 \%$ of the mass remains) occurs at $573{ }^{8} \mathrm{C}$ when it is heated at $10{ }^{8} \mathrm{C} / \mathrm{min}$ in an inet atmosphere. The decomposition occurs in at least two steps. The first step corresponds to the onset of the decomposition (at $\mathrm{T}_{95 \%}$ ). The maximum mass loss rate $(4.8 \mathrm{wt} \% / \mathrm{min})$ occurs at $608{ }_{\mathrm{C}}\left(\mathrm{T}_{\mathrm{MLR}}\right)$ and corresponds to a mass loss of around $18 \mathrm{wt} \%$. Indeed, a relatively sharp mass loss is observed on the TG curve in the temperature range of $500-700 \mathrm{C}$, whereby the mass loss is at around $35 \mathrm{wt} \%$. At higher

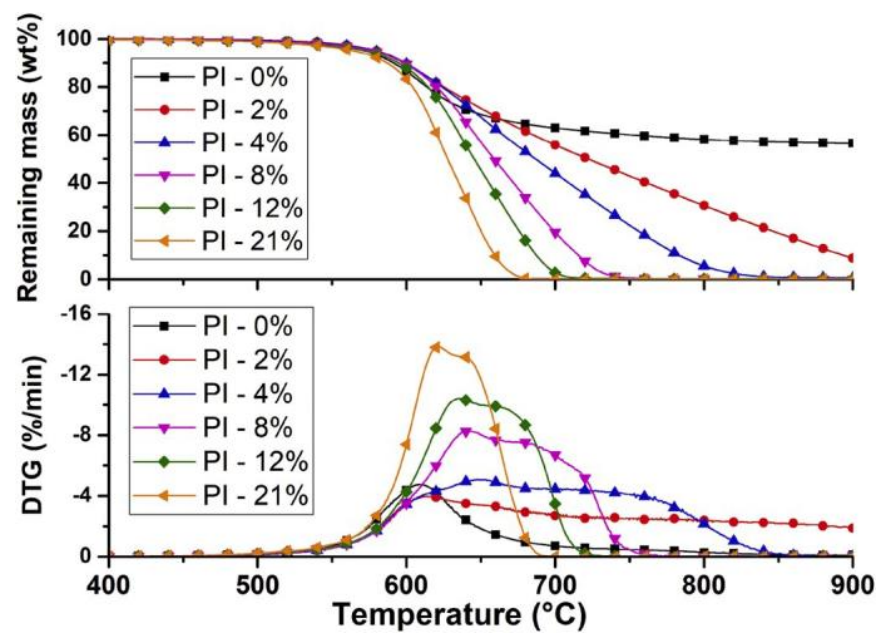

Fig. 1. TGA and DTG plot of PI heated at $10 \diamond_{\mathrm{C} / \mathrm{min}}$ under nitrogen, $2 \%, 4 \%$, $8 \%$ and $12 \% \mathrm{O}_{2}$, and under air. 
Table 1

Summary of the TGA of PI under nitrogen, $2 \%, 4 \%, 8 \%$ and $12 \% \mathrm{O}_{2}$, and under air.

\begin{tabular}{|c|c|c|c|c|}
\hline PI & $\mathrm{T}_{95 \%}\left(\otimes_{\mathrm{C}}\right)$ & $\left.\mathrm{T} @ \mathrm{MLR}_{\mathrm{MAX}} \otimes_{\mathrm{C}}\right)$ & $\operatorname{MLR}_{\text {MAX }}(\% / \min )$ & Residue (wt $\%$ ) \\
\hline $\mathbf{N}_{2}$ & 573 & 608 & 4.8 & 56 \\
\hline $2 \% \mathrm{O}_{2}$ & 575 & 612 & 4.0 & 9 \\
\hline $4 \% \mathrm{O}_{2}$ & 578 & 647 & 5.0 & 0 \\
\hline $8 \% \mathrm{O}_{2}$ & 577 & 642 & 8.2 & 0 \\
\hline $12 \% \mathrm{O}_{2}$ & 572 & 635 & 10.4 & 0 \\
\hline Air & 565 & 622 & 13.7 & 0 \\
\hline
\end{tabular}

temperatures, the mass loss rate is much lower, but is still detectable. This means that there are still decomposition reactions occurring in the material. This is assumed to be the second step of the decomposition. This step partly overlaps the first one and has a much lower mass loss rate. This second mass loss rate can be viewed as a pseudo shouldering of the DTG curve at 700-850 ${ }^{\circ}$. This means that there is a slow mass loss that occurs with increasing temperature and suggests that the virgin polymeric material has undergone a first, sharp decomposition step, forming a carbonaceous char, which is more robust thermally than the initial structure of the polymer. Moreover, with increasing temperature, some of the char formed, keeps on degrading at a slower rate. At $900{ }^{\diamond} \mathrm{C}$, there is still some mass loss that is recorded. This is confirmed by the non-zero mass loss rate at the same temperature. The residual mass at $900{ }^{\circ} \mathrm{C}$ is around $56 \mathrm{wt} \%$. This is a very high residual mass considering that this is a neat polymeric material.

To study the influence of oxygen on the thermal decomposition of PI, TG analysis under different oxygen concentrations were performed (Fig. 1, Table 1). One major step can be observed from the TGA plot of PI when it is heated at $10 \mathrm{C} / \mathrm{min}$ under $2 \%$ oxygen concentration. The temperature at the onset of the decomposition $\left(\mathrm{T}_{95 \%}\right)$ is observed at 575 ${ }_{\mathrm{C}}$. This temperature is relatively close to the onset of the decomposition of that under nitrogen, suggesting that the first decomposition may be independent on the atmosphere. Moreover, when comparing the maximum mass loss rates of PI under nitrogen $v s$ under $2 \%$ oxygen, it

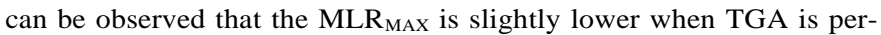
formed under a slightly oxidative atmosphere. However, it seems that the onset of the decomposition is closely followed by the other decomposition steps. This is evidenced by the DTG curve of PI under $2 \% \mathrm{O}_{2}$, which shows that it has a much higher mass loss rate at high temperatures $\left(>700 \diamond_{C}\right)$ under low oxygen concentrations than when the analysis is performed under inert atmosphere (approx. $0 \mathrm{wt} \% / \mathrm{min}$ under nitrogen and $z \mathrm{wt} \% / \mathrm{min}$ under $2 \% \mathrm{O}_{2}$ ). The explanation to this is that the mass loss at high temperatures is due to the oxidation of the char that is formed at lower temperatures (at the onset of the decomposition). Another observation is that the oxidation of the char seems to occur almost as soon as it is formed. The two apparent steps that were observable on the DTG curves from the TGA of PI, are therefore somewhat overlapping and undiscernible. From the TGA plots of PI under $4 \%$, $8 \%$ and $12 \%$ oxygen concentrations, it can be confirmed that an increase in oxygen concentration increases the extent of the apparent second step of the decomposition. It can also be observed on the DTG curves that there is a shift of the MLR $_{\max }$ towards higher temperatures as the oxygen concentration is increased. Indeed, under nitrogen, the MLR $\mathrm{MAX}_{\text {corre- }}$ sponds to a temperature of $610{ }_{\mathrm{C}}$ whereas under $12 \%$ oxygen, the MLR $_{\text {MAX }}$ corresponds to a temperature of $637{ }^{\diamond}$. This suggests that there may be a slight stabilization on the structure formed during the onset of the thermal decomposition. While it may be inferred that the presence of oxygen brings about some form of stability, it should be noted that the temperature ranges within which the stabilization occurs is very narrow.

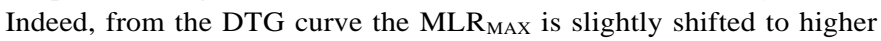
temperature, representing a slight stabilization. However, the MLR is much higher. This means that despite the slight stabilization, the polymer decomposes more quickly in the presence of oxygen than under nitrogen, possibly via another mechanism.

To complete the study concerning the thermal stability of PI, TGA was performed under synthetic air (Fig. 1, Table 1).

In air, the onset of the degradation corresponds to a temperature of $565{ }^{\circ}$. This temperature is slightly lower than when the analysis is performed under nitrogen $\left(\mathrm{T}_{95 \%}{ }^{1} 73{ }^{-} \mathrm{C}\right)$, suggesting that the thermal stability is slightly lower under oxidative atmospheres. The thermooxidative degradation seems to occur in a single step within the temperature range $550-700{ }^{\circ}$, whereby there is an abrupt mass loss from $100 \mathrm{wt} \%$ to $0 \mathrm{wt} \%$. However, the DTG curve shows two peaks at $622{ }^{\diamond} \mathrm{C}$ and at $638 \mathrm{C}$. This means that there are at least two different steps during the thermo-oxidative decomposition of PI. Moreover, the two DTG peaks are relatively close to each other. This means that the reaction steps are probably overlapped. Since the temperatures at the onset of the degradation are relatively close to each other whether the analysis is performed in air or under nitrogen, it means that there is a strong probability that the first step of the thermal decomposition still possesses a pyrolysis step which is closely followed by thermo oxidation.

\subsection{Identification of decomposition products of polyimide}

In order of identifying the decomposition products of PI, Pyrolysis Gas Chromatrography Mass Spectrometry (Py-GC/MS) was used. The gases evolving during pyrolysis of PI were identified and their intensity profiles are followed as a function of temperature (Fig. 2).

The temperature at which the different gases are evolved, provides information about the stages of the thermal decomposition. From the intensity profiles obtained by EGA-analysis, it can be observed that the first decomposition gases to be obtained are benzene, cyanobenzene and dicyanobenzene, detected at 540 and $560{ }^{\circ} \mathrm{C}$ respectively. There are some other early decomposition gases such as phenol, 4-aminophenol and aniline which are detected. Other identified decomposition products are: phthalimide, dibenzofuran, diphenylether and phthalanil. These structures are more reminiscent of depolymerized polyimide or the result of recombination reactions that may have occurred at high temperatures. The peak release intensities of the evolved gases all occur between 640 and $660{ }^{\circ} \mathrm{C}$. It should be noted that the evolution of water was also observed during the analysis of the evolved gases.

Moreover, TGA-FTIR was performed on PI in order to identify the pyrolysis gases that are evolved during its thermal decomposition. However, very few decomposition products were identified. The recorded chemigram obtained from the TGA-FTIR (not shown) permits to define the onset and almost the end of the degradation, which are respectably at $600{ }^{\mathrm{C}}$ and $733{ }_{\mathrm{C}}$, thus the FTIR spectra corresponding to those temperatures were analyzed (Fig. 3 and Fig. 4).

At the onset of the decomposition, only carbon dioxide and carbon monoxide are observed on the corresponding FTIR spectra. This means that oxygen-involving bonds are the first to be broken during the thermal decomposition mechanism of PI.

Absorption peaks corresponding to $\mathrm{CO}_{2}$ and $\mathrm{CO}$ are clearly visible on the FTIR spectrum that corresponds to the evolved gases released at 600 ${ }^{\circ}$. At higher temperatures $\left(733{ }^{\circ}\right)$, other characteristic dongaions such as those of hydrogen cyanide (approx. $3300 \mathrm{~cm}^{-1}$ ) and methane $\left(3018 \mathrm{~cm}^{-1}\right.$ ) and ammonia (two narrow peak elongations at 933 and $970 \mathrm{~cm}^{-1}$ ) can be distinguished among the other peaks. From the intensity profiles of these gases as well as the TG curve of PI recorded during the TGA-FTIR (Fig. 5) it can be observed that carbon dioxide and carbon monoxide are evolved in the highest proportions. A small amount of $\mathrm{CO}_{2}$ is recorded at low temperatures $\left(500{ }_{\mathrm{C}}\right)$ and corresponds to less than $2 \mathrm{wt} \%$ mass loss. Carbon monoxide starts to evolve at $550{ }^{\circ}$, corresponding to a mass loss of about $3 \mathrm{wt} \%$. The peak intensities corresponding to the maximum release of carbon dioxide and carbon monoxide are both recorded at $611{ }_{\mathrm{C}}$. At higher temperatures, the release of carbon dioxide and carbon monoxide decrease, as does the mass loss rate (Fig. 1). However, as the amount of $\mathrm{CO}_{2}$ and $\mathrm{CO}$ are decreased, other decomposition gases are released. Indeed, as from 611 ${ }^{-} \mathrm{C}$, the intensity profiles of hydrogen cyanide, methane and ammonia start to increase. It should be noted that the intensity of these gases is 


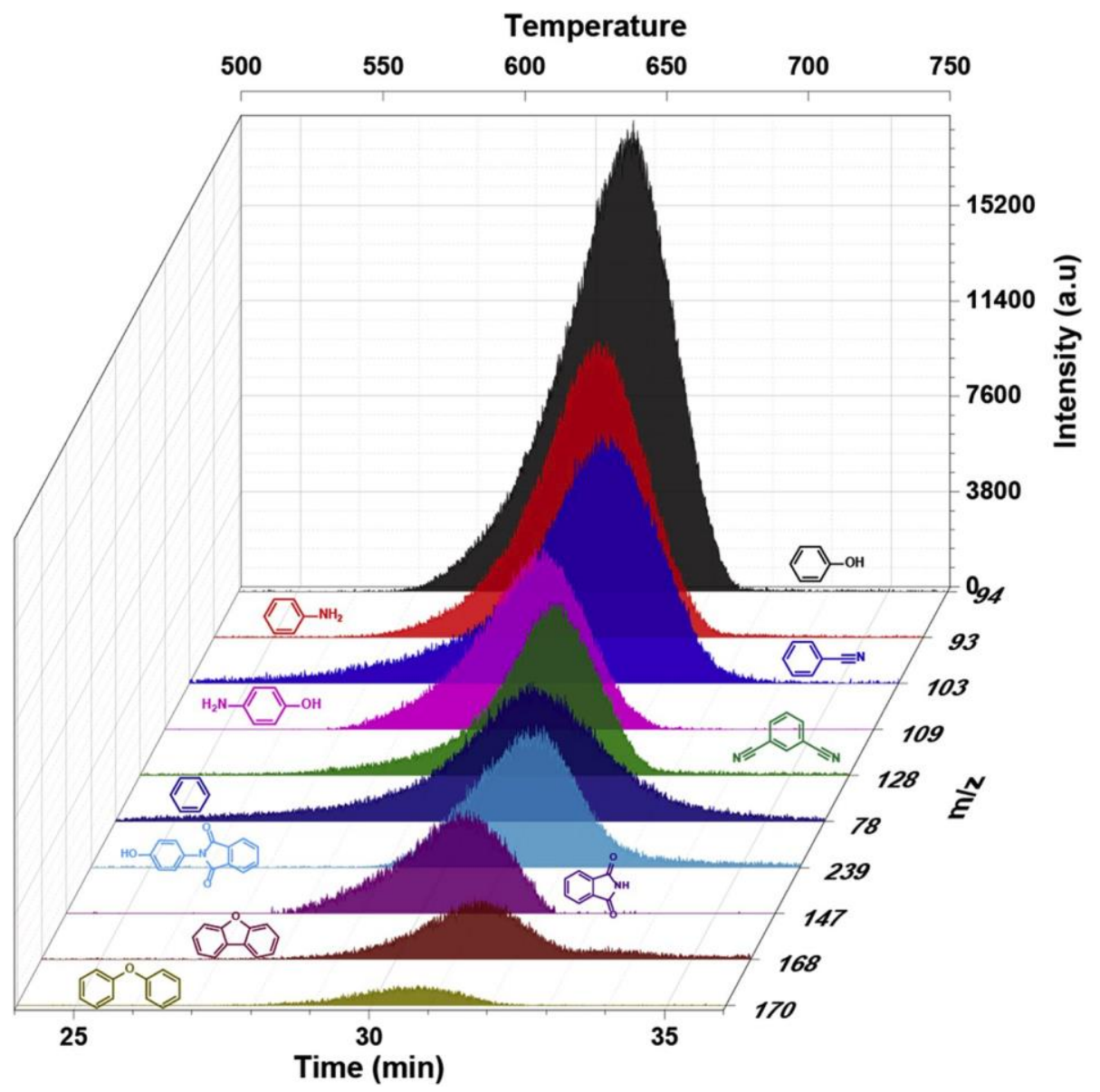

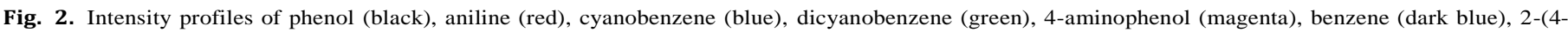

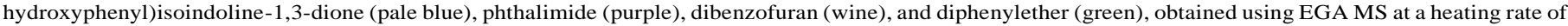
$20 \mathrm{C} / \mathrm{min}$. (For interpretation of the references to colour in this figure legend, the reader is referred to the Web version of this article.)

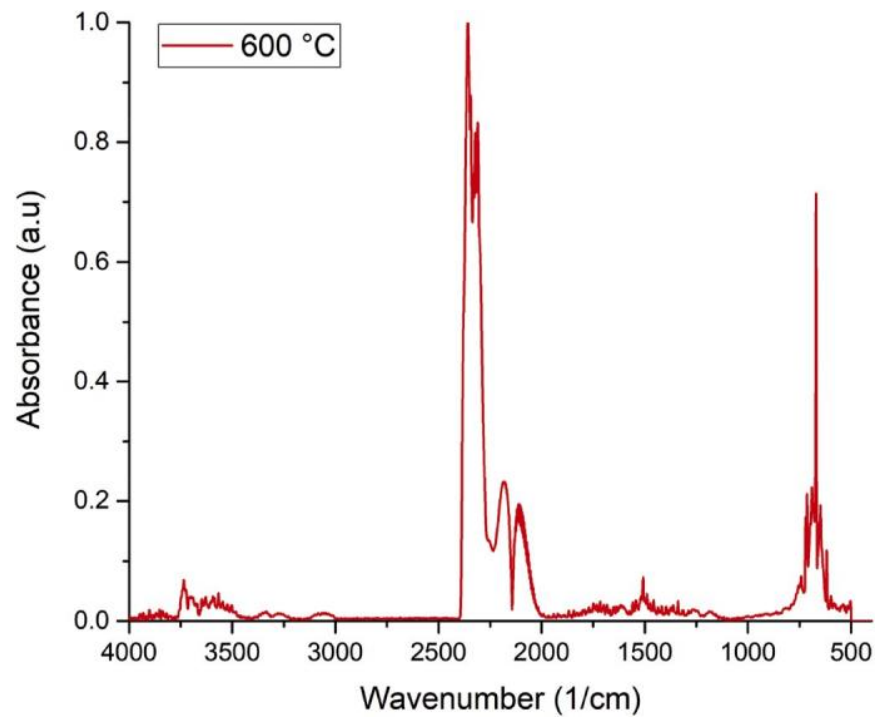

Fig. 3. FTIR spectrum corresponding to decomposition gases of PI released at $600{ }_{\mathrm{C}}$ under nitrogen.

inexistent at lower temperatures, but only starts to increase when the peak release of $\mathrm{CO}_{2}$ and $\mathrm{CO}$ has been reached. This suggests that first part of the decomposition, whereby $\mathrm{CO}$ and $\mathrm{CO}_{2}$ are released, corresponds to the formation of a char and that at higher temperatures, this

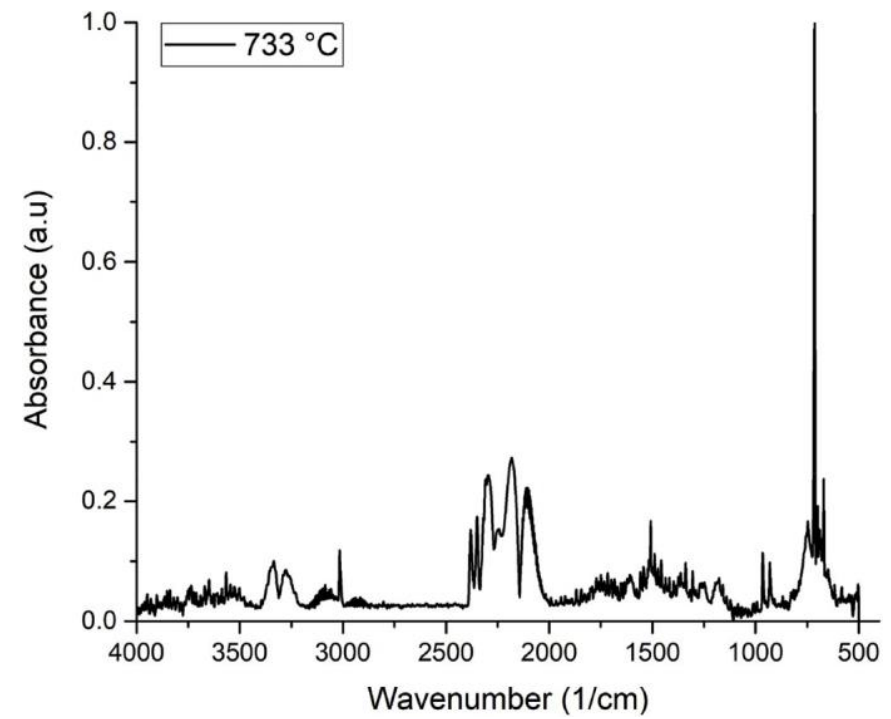

Fig. 4. FTIR spectrum corresponding to the decomposition gases released from $\mathrm{PI}$ at $733 \diamond \mathrm{C}$ under nitrogen.

char starts to decompose, causing the release other decomposition products.

It is noteworthy that py-GC/MS do not permits to identify small molecules such as methane and ammonia, which were identified thanks 


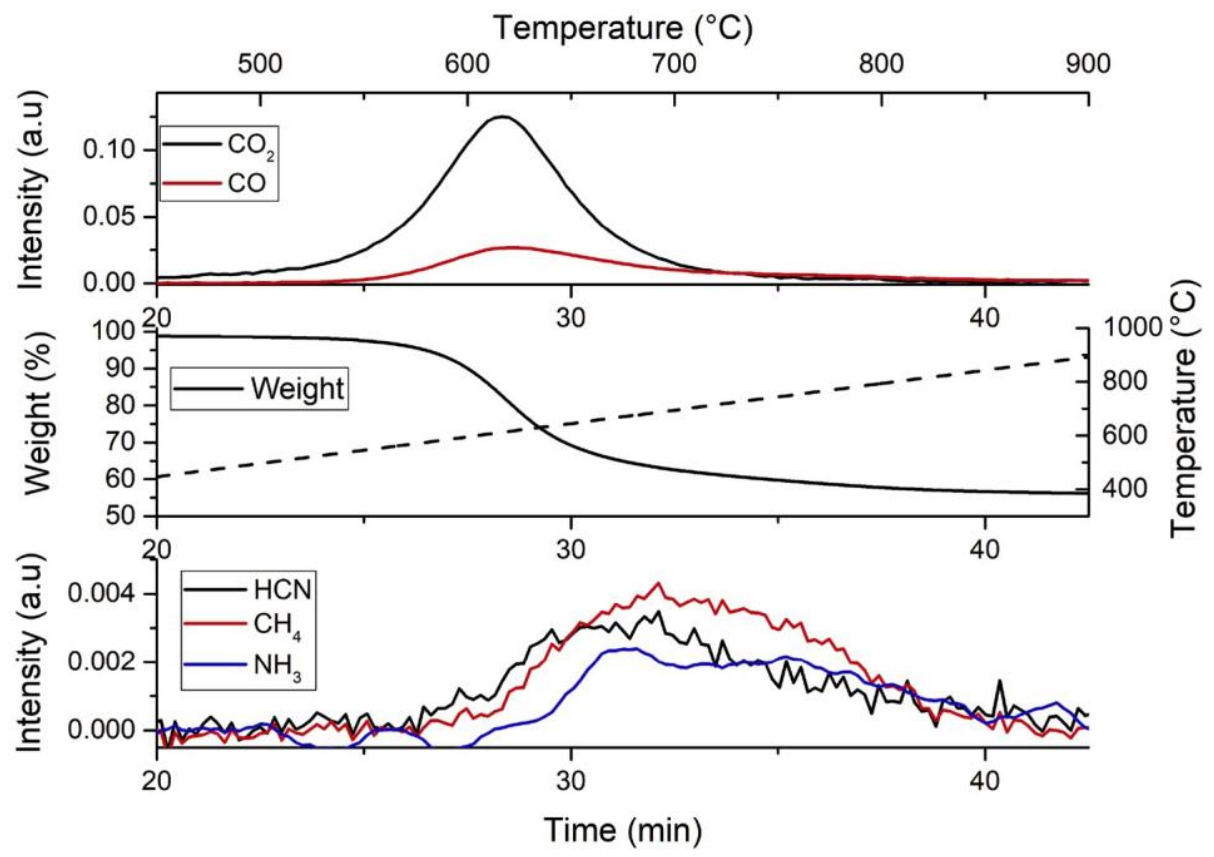

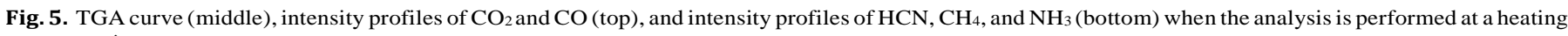
rate of $20{ }^{\ominus} / \mathrm{min}$.

to TGA -FTIR and their intensity profiles were plotted (Fig. 5). We have also seen that with respect to carbon dioxide and carbon monoxide, the amount of volatiles released is relatively low. This suggests that in a fire scenario, there might be a low amount of fuel generation during the thermal decomposition of the material. To be confirmed, the fire behavior of PI was evaluated by Mass Loss Calorimetry (MLC).

\subsection{Fire behavior of polyimide}

As a high-performance polymeric material, PI is expected to have good fire properties. To evaluate these properties, MLC experiments were carried out at three different heat fluxes: 35,50 , and $60 \mathrm{~kW} / \mathrm{m}^{2}$ and the temperature at the back of the sample was also recorded (Fig. 6). At $35 \mathrm{~kW} / \mathrm{m}^{2}$; there is no HRR recorded on the MLC experiment. The temperature at the back of the sample increases rapidly to around $400{ }^{\otimes} \mathrm{C}$ and remains then constant for the whole experiment. Visually, some

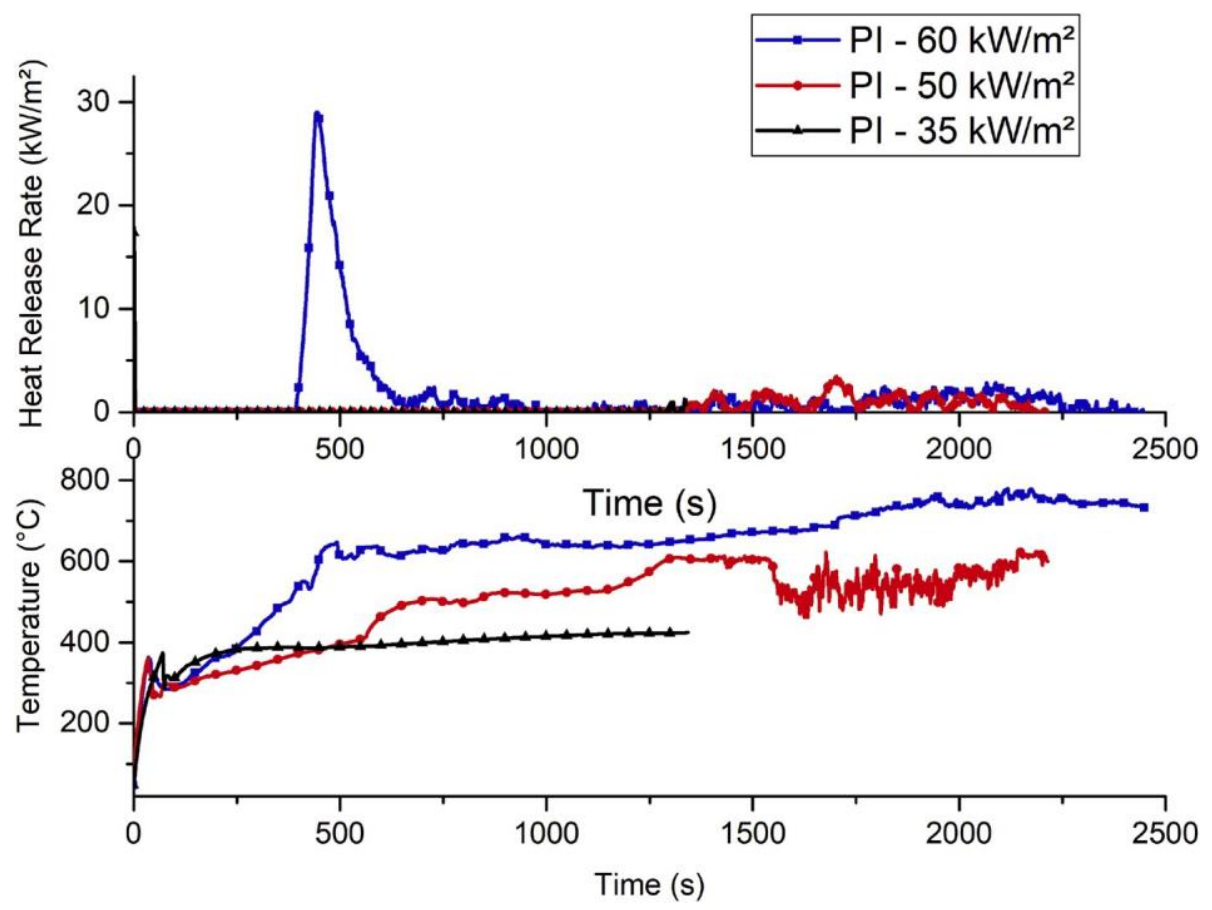

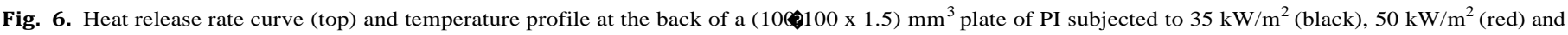

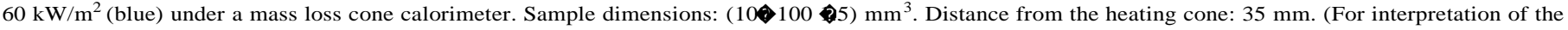
references to colour in this figure legend, the reader is referred to the Web version of this article.) 
deformation is observed on the material (shrinkage), but neither melting nor fumes are seen. From the HRR curve obtained when PI is subjected to an incident heat flux of $50 \mathrm{~kW} / \mathrm{m}^{2}$, it can be observed that the heat release rate is almost null throughout the experiment. There was no ignition of the material. Some values of HRR are recorded but it can be considered they are not significant even though we should recognize thermo-oxidation should occur at the surface of the material. Moreover, when looking at the temperature profile at the back of the sample, a rapid increase from room temperature to around $300{ }^{\circ} \mathrm{C}$ is observed in the first seconds of the test. After this, there is a steady increase in temperature until around $700 \mathrm{~s}$, whereby a more rapid temperature increase until around $600{ }^{\circ}$ is observed. Extensive thermal and thermooxidative decomposition occurs at this temperature.

The visual aspect of the material also changes throughout the test. At first, a slight swelling of the material is observed (Fig. 7, left). After around $564 \mathrm{~s}$, the material is clearly degraded (Fig. 7, middle) and fumes can be seen leaving the surface of the material. The decomposition of the material continues during the experiment which can be observed with the presence of a white residues on the top of the polymer (Fig. 7, right).

The thermal decomposition and thermo-oxidation of the sample pursued without the presence of a flame for several minutes. However, the visual aspect of the decomposing material did not change greatly during this time (Fig. 8, right and center). When the sample was removed, it could be noticed that there was significant degradation that had occurred on the sample. The polymer had almost completely degraded, leaving only bits and pieces of a charred solid on the sample holder (Fig. 8, right). The absence of ignition is assigned to the high amount of carbon dioxide and carbon monoxide released during the thermal decomposition, as seen by TGA-FTIR. These gases dilute the

flammable gases which are also released during the decomposition process. The resulting concentration of flammable gases is therefore lower than the critical concentration required for ignition to occur.

Since flaming combustion was not observed during the MLC at 50 $\mathrm{kW} / \mathrm{m}^{2}$, the sample was subjected to a higher heat flux $\left(60 \mathrm{~kW} / \mathrm{m}^{2}\right)$.

Under this heat flux, the PI ignites at 394s with a peak of heat release rate at $446 \mathrm{~s}$ (Fig. 6). However, despite the high incident heat flux on the material, one may notice that the visual aspect of the flame corresponds to a small one (Fig. 9, right). The HRR increases sharply until around 30 $\mathrm{kW} / \mathrm{m}^{2}$ and decreases as sharply to a very low HRR. This low value is maintained for the rest of the experiment.

The temperature profile, on the other hand, increases sharply upon exposition to the heat source (Fig. 6). This is accompanied by a slight swelling of the material and the formation of some fissures (Fig. 10, left). This increase peaks at $375{ }^{\circ} \mathrm{C}$ and a slight decrease in temperature is recorded. However, this decrease in temperature does not last for long, as it is closely followed by a steady rise in temperature until around 600 ${ }_{\mathrm{C}}$ whereby further deformation of the material is observed (Fig. 10, middle).

After ignition, the temperature at the back of the sample keeps increasing, albeit at a relatively low rate, from $613 \diamond_{\mathrm{C}}$ to $760{ }^{\diamond} \mathrm{C}$. This can be explained by the flaming of the material which feeds heat back to the sample. Quickly after the peak HRR was observed (around $460 \mathrm{~s}$ ), both the HRR and the size of the flame had greatly diminished (Fig. 10, left). As the experiment carried on, the HRR remained relatively close to zero.
There was a constant, barely visible flame throughout the process (Fig. 10, middle, encircled in blue). This flame also explains the non-zero value of the HRR until the end of the experiment. Despite the absence of the flame, combustion (oxidation) of the material is occurring. Indeed, at the end of the experiment, the presence of some white ash on the surface of the material strongly suggests that the polymer has endured combustion.

\subsection{Thermal decomposition reactions of PI}

It was observed that despite being subjected to a high heat flux, the heat release rate of PI remained relatively low $\left(\mathrm{HRR}<30 \mathrm{~kW} / \mathrm{m}^{2}\right.$ under $60 \mathrm{kWm}$ [2]). In an attempt to explain this low heat release rate on a molecular level, the thermal decomposition pathway of PI has been studied.

Pyrolysis GC/MS and TGA-FTIR experiments have allowed us to identify different decomposition products that are evolved when PI is subjected to high temperatures.

The initiation decomposition reactions that may occur correspond to either the imide ring cleavage or the cleavage of the carbon nitrogen bond between the phenyl and the imide. The suggested decomposition pathway in the early stage of the thermal degradation of PI is described in Ref. [21]. From this, a deeper reasoning towards the formation of the products from the thermal decomposition of PI was attempted. A schematic representation of the pathways that can be adopted during the thermal breakdown of PI is shown on Scheme 1. According to the decomposition products that were identified during the thermal decomposition of PI, random scission was identified as a probable pathway that is undertaken during the decomposition of PI. The easiest bond to break being the $\mathrm{C}-\mathrm{N}$ bond between the phenyl and the nitrogen, a bisimide diradical is formed. This diradical can rearrange to form a carbonyl isocyanate. An attack of the double bond on the carbonyl CO leads to the formation of carbon dioxide and isophthalonitrile (red route, Scheme 1). Moreover, random scission of the ether bonds may lead to some small aromatics such as phenol (blue route, Scheme 1) or benzene (magenta, Scheme 1). However, if the cleavage is between two $\mathrm{C}-\mathrm{N}$ bonds from the phenyl-imide linkage, it leads to the formation of diphenylether (pink route, Scheme 1) which was identified via PyGC/MS. Opening of the imide ring can also lead to different decomposition products. Indeed, if the ring opening occurs between the $\mathrm{C}-\mathrm{C}$ bond between the phenyl and the carbonyl, it leads to the formation of two carbon monoxide and an amine end. Further decomposition of this part of the chain would lead to the formation of aniline and aminophenol with the cleavage of the next ether linkage (violet, Scheme 1).

The formation of dibenzofuran can be explained by a two-step process. One, which occurs at low temperature, leading to the formation of the furan moiety on the polymer backbone, and another whereby random scission of the backbone leads to the release of dibenzofuran (turquoise route on Scheme 1). Abstraction of two hydrogens from adjacent phenyl from the diphenylether moiety at low temperatures would lead to the formation of a dibenzofuran structure that can be liberated at high temperatures upon cleavage of two opposite imide/ phenyl linkages. In order to explain the formation of 2-(4-hydroxyphenyl)isoindoline-1,3-dione (brown route, Scheme 1) the imide ring
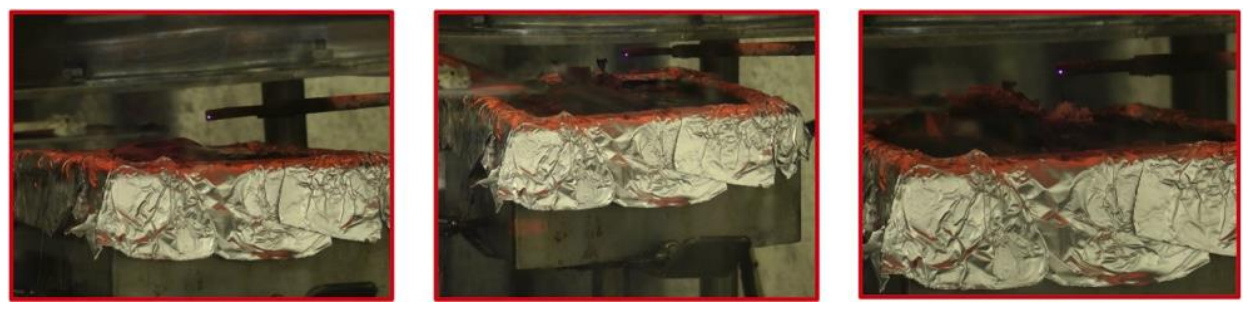

Fig. 7. Pictures taken of PI when subjected to $50 \mathrm{~kW} / \mathrm{m}^{2}$ at different times during the experiment: $120 \mathrm{~s}$ (left), $564 \mathrm{~s}$ (middle), $1300 \mathrm{~s}$ (right). 

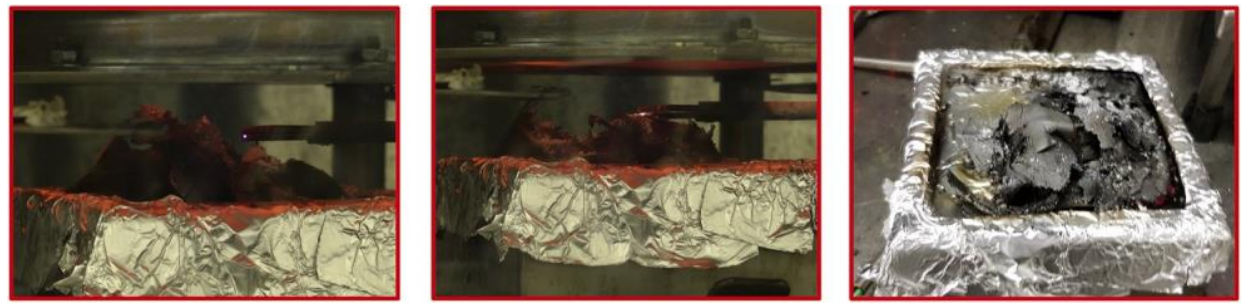

Fig. 8. Pictures taken of PI when subjected to $50 \mathrm{~kW} / \mathrm{m}^{2}$ at $1541 \mathrm{~s}$ (left), before removing sample (middle), and after the removal of the sample from the heat source (right)
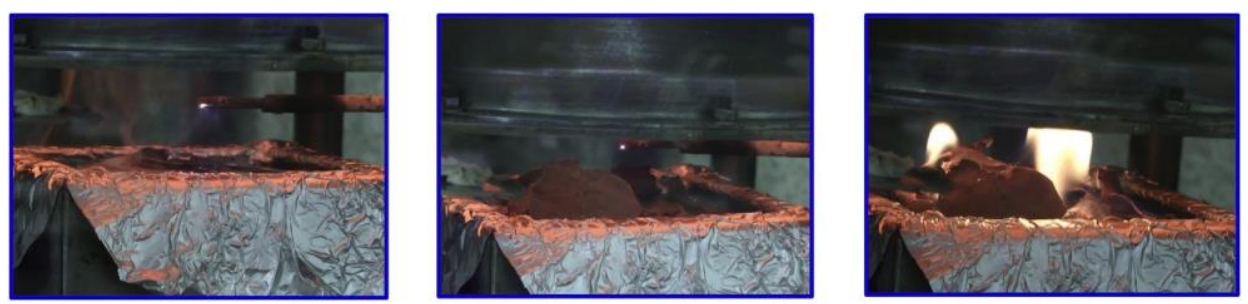

Fig. 9. Pictures taken of PI when subjected to $60 \mathrm{~kW} / \mathrm{m}^{2}$ at different times during the experiment: $60 \mathrm{~s}$ (left), $360 \mathrm{~s}$ (middle), $401 \mathrm{~s}$ (right).
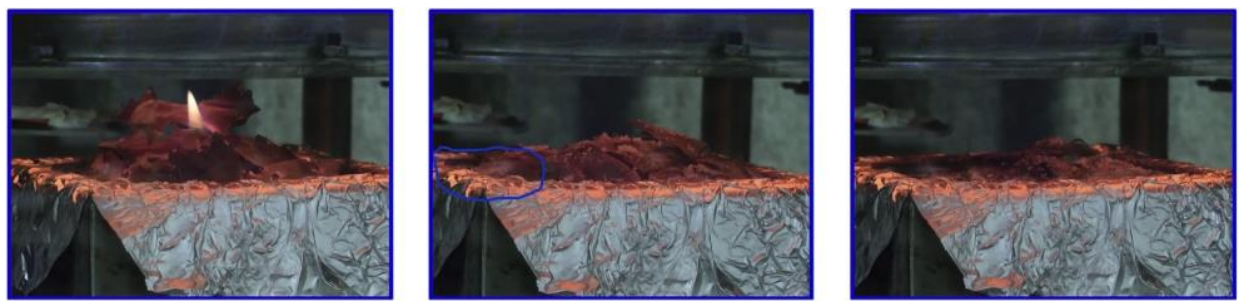

Fig. 10. Pictures taken of PI when subjected to $60 \mathrm{~kW} / \mathrm{m}^{2}$ at different times during the experiment: $511 \mathrm{~s}$ (left), $1500 \mathrm{~s}$ (middle), $2400 \mathrm{~s}$ (right).

must first be cleaved on the aromatic side. This leaves a phenyl diradical linked to another imide group on the other side. Cleavage of the ether bond that is opposite to this imide ring leads to the formation of the 2-(4hydroxyphenyl)isoindoline-1,3-dione tri-radical. This radical can easily abstract three hydrogens, giving rise to 2-(4-hydroxyphenyl)isoindoline1,3-dione. Similarly, the formation of phthalimide comes from the same initial reaction, whereby one of the two imide rings on the same phenyl is decomposed. However, the subsequent cleavage comes from that of the imide-phenyl bond (green route, Scheme 1), leading to phthalimide.

It should be noted that the fire behavior of PI did not lead to a high amount of char. Moreover, the absence of a significant flame during the mass loss cone test implies that there is a high probability that thermooxidation is occurring at the polymer/air interface. This means that most of the volatile products that are released during the thermal decomposition of the material in a mass loss cone, is being oxidized on the surface of the material.

Despite the release of flammable substances upon its thermal decomposition, PI also releases non-flammable derivatives such as carbon dioxide and carbon monoxide. This means that only part of the gases evolved during the thermal decomposition of PI have the potential of feeding an eventual flame. Moreover, among the volatile products, the presence of these non-flammable gases dilutes the concentration of combustibles, causing a lower concentration of fuel for ignition and/or the sustaining of an eventual flame.

\section{Conclusions}

From TGA measurements, we have seen that PI has exceptional thermal stability both in inert and thermo-oxidative conditions, indeed, it has a relatively high decomposition temperature $\left(>500{ }^{\circ}\right.$ ). PI can form a little amount of char when it is heated under inert conditions. We have seen that under oxidative atmosphere, this char already starts to degrade at the onset of the decomposition. However, despite a higher rate of degradation in air, the temperature at which the onset of the thermal decomposition of PI occurs is relatively close to that under nitrogen.

Moreover, the mass loss cone calorimetry tests performed on PI have shown the enviable fire properties of PI. Indeed, the material does not catch fire at all when it is subjected to a high incident heat flux of $50 \mathrm{~kW} /$ $\mathrm{m}^{2}$. It does, nonetheless, ignite at a higher heat flux of $60 \mathrm{~kW} / \mathrm{m}^{2}$, but only to achieve a peak heat release rate of around $30 \mathrm{~kW} / \mathrm{m}^{2}$. It should also be noted that despite the low heat release rate recorded, the material does undergo thermal decomposition when it is subjected to such high heat fluxes. It is highly likely that the underlying phenomenon that is undergone during the experiment corresponds to the thermooxidation of PI. This can be inferred because hardly any flame is visible during the experiment, suggesting that oxygen is effectively present near the surface of the material.

The degradation of the char in the presence of oxygen is evidenced by TGA under different oxygen levels. Indeed, some it could be argued that the presence of a small flame would mean that the immediate surrounding environment of the material can be considered poor in oxygen (intermediate region between the flame and the bulk of the material). However, despite being in oxygen poor environment, thermo-oxidation of PI does occur, as it can be seen on Fig. 1, whereby a non-zero mass loss rate is observed despite being at a relatively low oxygen concentration $(2 \%)$

Furthermore, the decomposition pathway of PI was also investigated. The main decomposition reactions occurring in polyimide involve the scission of the imide ring and that carbon-carbon bond between the 


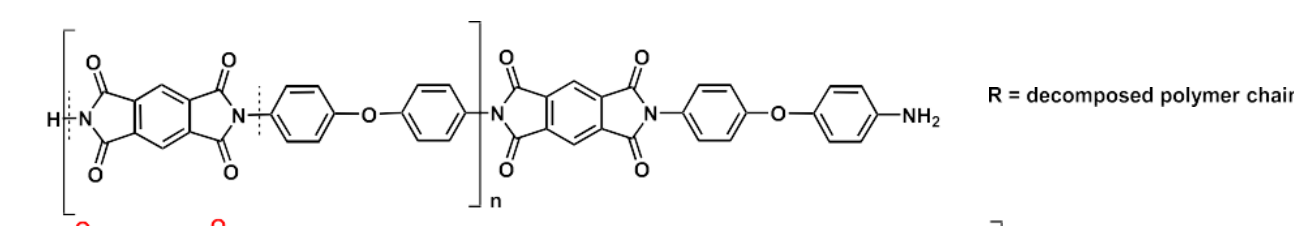

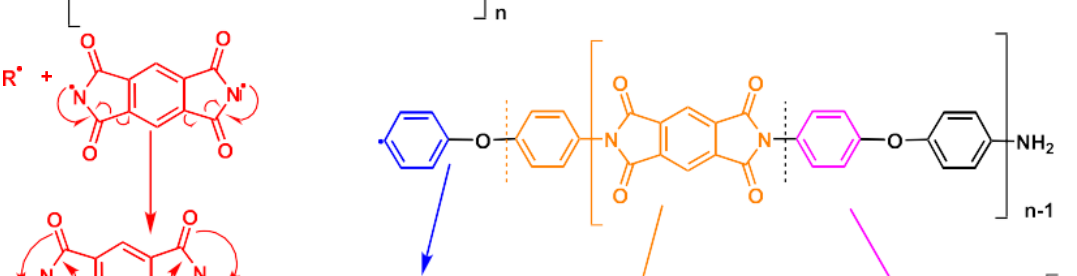

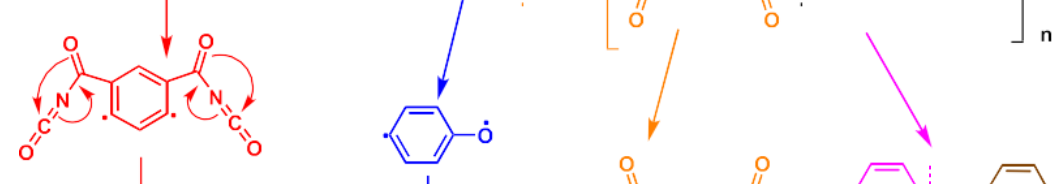

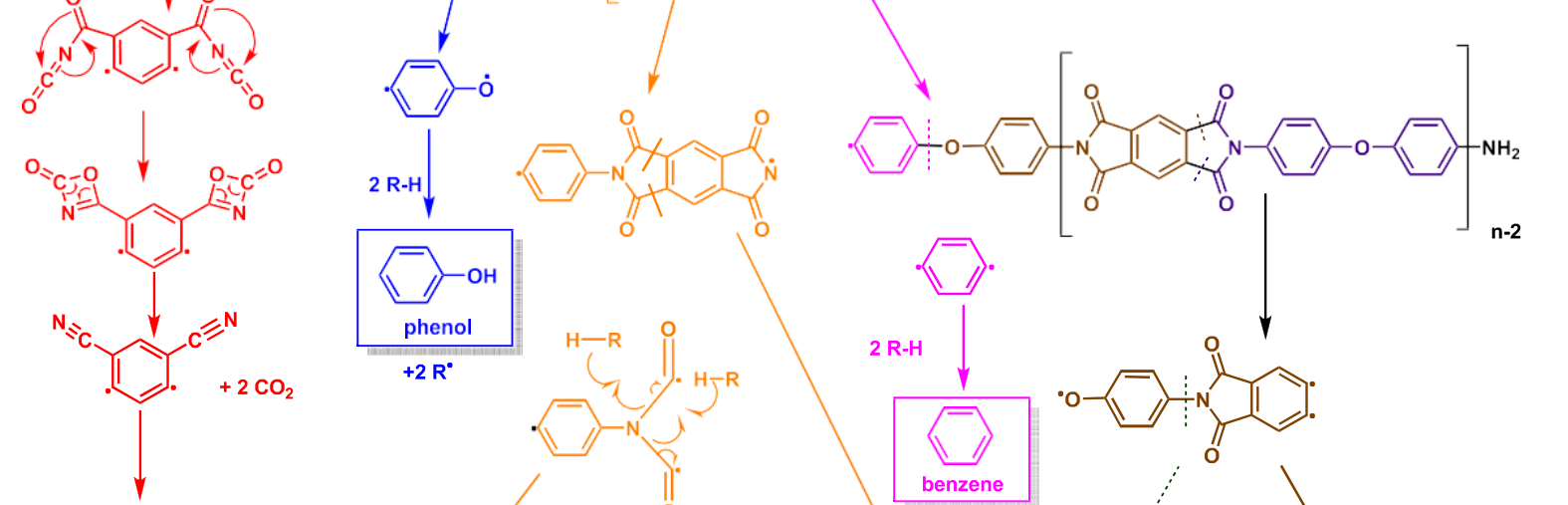

"no"

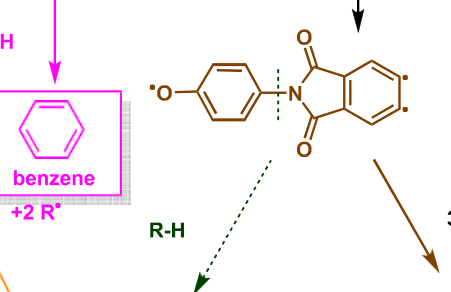

atson

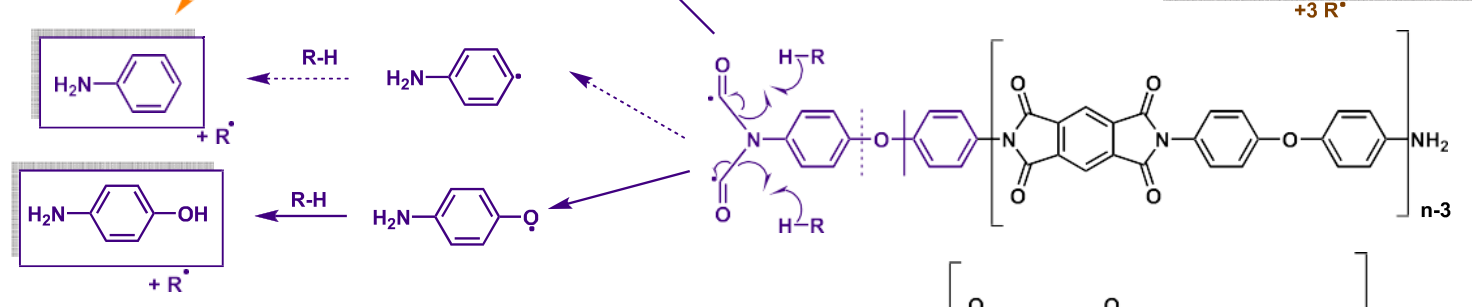

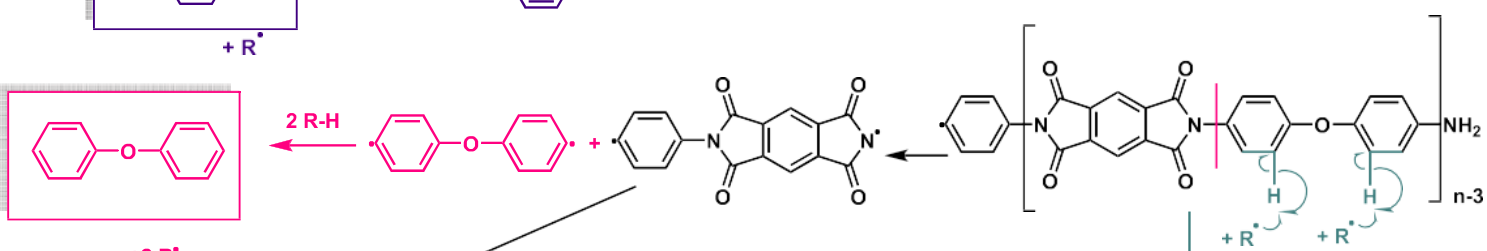

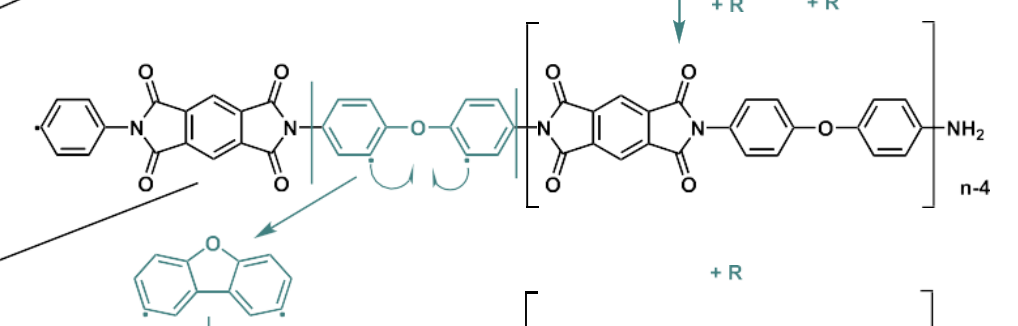

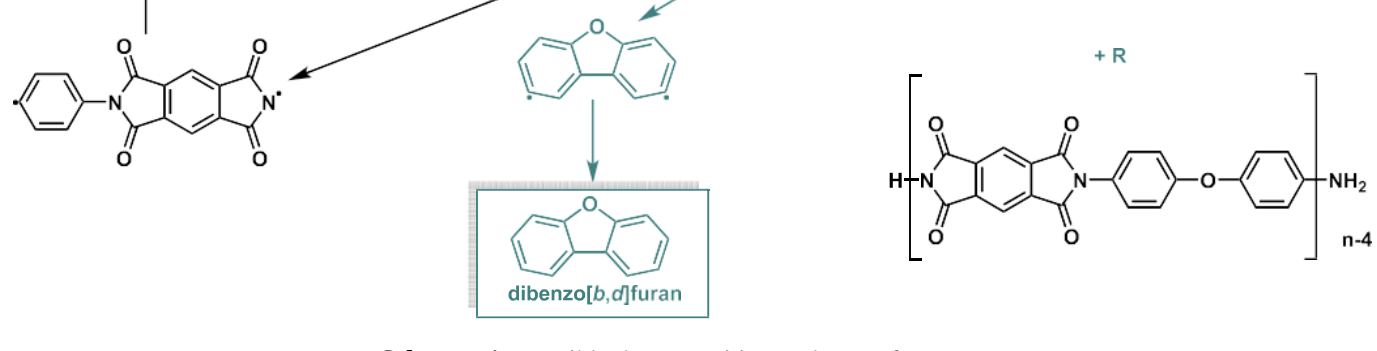


imide ring and the phenyl. Subsequently, phenyl derivatives containing $\mathrm{CN}, \mathrm{OH}$, and $\mathrm{NH}_{2}$ are generated. Moreover, it is also possible that the imide ring remains intact, generating phthalimide and 2-(4-hydroxyphenyl)isoindoline-1,3-dione. These are non-inflammable and may contribute to the dilution of an eventual flame.

\section{Declaration of competing interest}

The authors declare that they have no known competing financial interests or personal relationships that could have appeared to influence the work reported in this paper.

\section{Acknowledgements}

This work has received funding from the European Research Council (ERC) under the European Union's H2020 - the Framework Programme for Research and Innovation (2014-2020) ERC Grant Advances Agreement $\mathrm{N} \bullet 670747$-ERC 2014 AdG/FireBar-Concept for FireBar Concept project.

\section{Appendix A. Supplementary data}

Supplementary data to this article can be found online at https://doi. org/10.1016/j.firesaf.2020.103060.

\section{References}

[1] V. Mittal, High performance polymers: an overview, Wiley, Hoboken, 2011, pp. 1-20.

[2] A. Ramgobin, G. Fontaine, S. Bourbigot, Thermal degradation and fire behavior of high performance polymers, Polym. Rev. 59 (1) (2019) 55-123.

[3] J.M. Vazquez, R.J. Cano, B.J. Jensen, E.S. Weiser, Polyimide Foams. US Patent 6 956 066, Assigned to the United States of America as Represented by the Administrator of the National Aeronautics and Space Administration, 2005 Washington, DC.
[4] Macheras JT. Fluid Separation Membranes Prepared from Blends of Polyimide Polymers. US patent 5635 067, assigned to Praxair Technology, Inc., Danbury, CT; 1997.

[5] K.L. Mittal (Ed.), Polyimides: Synthesis, Characterization and Applications, Plenum, New York, 1984

[6] G.H. Melton, E.N. Peters, R.K. Arisman, Engineering thermoplastics, in: Applied Plastics Engineering Handbook, Elsevier, 2011, pp. 7-21.

[7] P.W. Morgan, S.L. Kwolek, Polyamides from phenplenediamines and aliphatic diacids, Macromolecules 8 (1975) 104-111.

[8] B.L. Deopura, N.V. Padaki, Synthetic Textile Fibres: Polyamide, Polyester and Aramid Fibres, Elsevier Ltd, 2014.

[9] J.A. Cella, Degradation and stability of polyimides, Polym. Degrad. Stabil. 36 (2) (1992) 99-110.

[10] R.E. Lyon, M.L. Janssens, Polymer flammability, in: Encyclopedia of Polymer Science and Technology, Wiley, 2015, pp. 1-70.

[11] H. Zhang, Fire-Safe Polymers and Polymer Composites, DOT/FAA/AR, 2004 pp. 1-209. September.

[12] (a) S. Bourbigot, X. Flambard, F. Poutch, Study of the thermal degradation of high performance fibres - application to polybenzazole and p-aramid fibres, Polym. Degrad. Stabil. 74 (2) (2001) 283-290;

(b) K.E. Perepelkin, E.N. Dresvyanina, E.A. Pakshver, Thermal characteristics of high-strength and thermostable Aromatic fibres, Fibre Chem. 40 (3) (2008) 266-269.

[13] K.E. Perepelkin, E.N. Dresvyanina, E.A. Pakshver, Thermal characteristics of highstrength and thermostable Aromatic fibres, Fibre Chem. 40 (3) (2008) 266-269.

[14] J.K. Fink, Poly(Imide)S, High Perform. Polym. (2014) 343-372.

[15] K.L. Mittal (Ed.), Polyimides: Synthesis, Characterization and Applications, Plenum, New York, 1984.

[16] C.A. Harper, Thermoplastics, McGraw Hill Professional, Access Engineering, Ohio, 2000.

[17] R.E. Lyon, M.L. Janssens, Polymer Flammability, Report, 2015.

[18] ISO 13927:2015, Plastics - Simple Heat Release Test Using a Conical Radiant Heater and a Thermopile Detector, 2015

[19] ASTM International, ASTM E906/E906M-17, Standard Test Method for Heat and Visible Smoke Release Rates for Materials and Products Using a Thermopile Method, 2017.

[20] E. Guillaume, L. Saragoza, Methane calibration burner and C-factor determination with cone calorimeter - validation of the standardized calibration protocol, Fire Mater. 40 (3) (2016) 511-515.

[21] H. Hatori, Y. Yamada, M. Shiraishi, M. Yoshihara, T. Kimura, The mechanism of polyimide pyrolysis in the early stage, Carbon N. Y. 34 (2) (1996) 201-208. 